\title{
El hito urbano como mensaje. Arquitectura, comunicación y valores corporativos
}

Julia Rey Pérez | julreyper@alum.us.es

Víctor Hernández-Santaolalla | vhsantaolalla@us.es

UNIVERSIDAD DE SEVILLA

Resumen: Desde sus orígenes, la arquitectura se ha puesto al servicio de quienes ostentan el poder con el objetivo de comunicar su posición autoritaria respecto al resto de ciudadanos. Esta tradición fue posteriormente heredada por las empresas y entidades públicas, como una forma más de difundir su identidad corporativa y ganar notoriedad, para lo cual contratan arquitectos de fama internacional. En el presente artículo se trabaja en torno a los conceptos de arquitectura y comunicación. En él se aborda la cuestión de cómo, en ocasiones, la marca del promotor queda supeditada a la marca del arquitecto.

Palabras clave: paisaje urbano, identidad corporativa, marca, arquitecto, comunicación.

Abstract: Since its origins, architecture has been at the service of those who hold power in order to communicate their authoritarian position over the rest of the citizens. This tradition was later inherited by companies and public institutions as a way of spreading their corporate identity and gain notoriety, for which they hire internationally renowned architects. This paper addresses the concepts of architecture and communication, and analyses the question of how, sometimes, the developer's brand is subordinated to the architect's brand.

Key words: urban landscape, corporate identity, brand, architect, communication. 


\section{La arquitectura como recurso comunicativo desde una perspectiva histórica}

Desde el inicio de las civilizaciones, la arquitectura ha sido un instrumento al servicio de la comunicación informativa y persuasiva, instrumentalidad que, por otra parte, le ha otorgado un notable papel en la transmisión del poder y la ha encumbrado como absoluta protagonista del paisaje urbano. El poblado andino de Machu Picchu, las pirámides de Egipto, las catedrales de la Edad Media o las iglesias y basílicas del Renacimiento, evidencian cómo el poder religioso, siempre ligado al político, ha recurrido a imponentes obras arquitectónicas para manifestar su autoridad y supremacía jerárquicas y, al mismo tiempo, infundir respeto, admiración e incluso temor a los ciudadanos, a los que solo les restaba rendirse a la grandiosidad de sus gobernantes (Caro, 1996: 75). Se trata de obras de las que raramente se conoce el nombre de sus arquitectos, pues no será hasta la llegada del periodo renacentista cuando la creación anónima y colectiva deje paso a figuras como Michelangelo Buonarroti, Fillippo Bruneleschi, Andrea Palladio o Rafaello Sanzio. Es justo en esta época cuando comienzan a aparecer los primeros tratados arquitectónicos, dirigidos a la nobleza y a los príncipes, los grandes mecenas de los arquitectos. De esta forma, el arquitecto se desvincula del maestro (artesano, de origen popular y asociado a actividades manuales) y ocupa un puesto en la elite social al adquirir la categoría de artista: noble, académico, intelectual y, ante todo, un individuo (Benévolo, 1985).

Con la Revolución Industrial (1880-1914) y la aparición del turismo como forma de ocio, se da paso a una nueva etapa en el desarrollo de la arquitectura. Si bien hasta el momento su función simbólica se vinculaba primordialmente con el poder religioso o político, el nacimiento del capitalismo dará paso a otro gran emisor: las grandes empresas, que propician unos nuevos elementos urbanos que, entendidos prácticamente como nuevas catedrales -"catedrales del dinero" (Caro González, 1996: 75)-, se verán obligados a generar sus propios iconos en un intento por transmitir los valores corporativos propios y diferenciados de los del resto de empresas, y con tal fin contratan a los arquitectos más destacados del panorama internacional. En este contexto, EEUU es el país que mejor representa este cambio de paradigma. La finalización de la Primera Guerra Mundial lo convierte en un país meritorio, donde surge un deseo espontáneo de exaltar el triunfo de la democracia y el progreso (Frampton, 1998: 222). En Nueva York, el vertiginoso desarrollo económico de principios de siglo encontraba su traslación en el paisaje urbano en el rápido crecimiento de los rascacielos de la isla de Manhattan.

El conjunto de edificios que se alzaban sobre el plano de Wall Street dejaban muy clara la función del lugar: un espacio para poder acoger a todos los empleados que se dedicaban a la gestión administrativa, lo que justificó la construcción en altura y el máximo aprovechamiento de la zona. De esta forma, el centro urbano se convirtió, primordialmente, en un lugar de trabajo donde se concentraba el dinero y el poder de la ciudad, lo cual traspasa las fronteras de la mera funcionalidad, abriendo paso a la transmisión de una identidad de marca bien definida y cuyos valores son igualmente perceptibles tanto por el 
ejecutivo que tiene allí sus oficinas como por el inmigrante que llega a Nueva York con la confianza de que allí alcanzará el éxito (Vercelloni, 1996: 238).

El desarrollo económico se transformó en audacia tecnológica. La construcción de estos rascacielos se convirtió en una obsesión que afectó a arquitectos, directivos y administradores públicos durante los años veinte. La capacidad de generar riqueza se convirtió en una condición antropológico-cultural de la época y se manifestó en la construcción de rascacielos. Esta euforia psicológica, los resultados de la bolsa y la producción de bienes se materializaron en Manhattan. La utilización de los perfiles de acero permitió la elevación en altura de estos hitos que acogían el aparato productivo de dicha ciudad. Las nuevas formas, las alturas impresionantes, los nuevos materiales (vidrio y acero) y una composición arquitectónica innovadora transfieren un mensaje que define los valores por lo que hoy día es reconocida Manhattan en cualquier parte del mundo (Vercelloni, 1993: 240). El edificio Chrysler (1928-1930), el Waldorf Astoria (1931), el Rockefeller Center (1932-1939) o el edificio administrativo de la Johnson Wax, que Herbert Hib Johnson encargó a Frank Lloyd Wright (1936-1939), son algunos de los ejemplos más inmediatos de esta nueva tradición arquitectónica, a los que seguirán otros como el edificio Seagram (1958), diseñado por el arquitecto alemán Mies Van der Rohe (Figura 1).

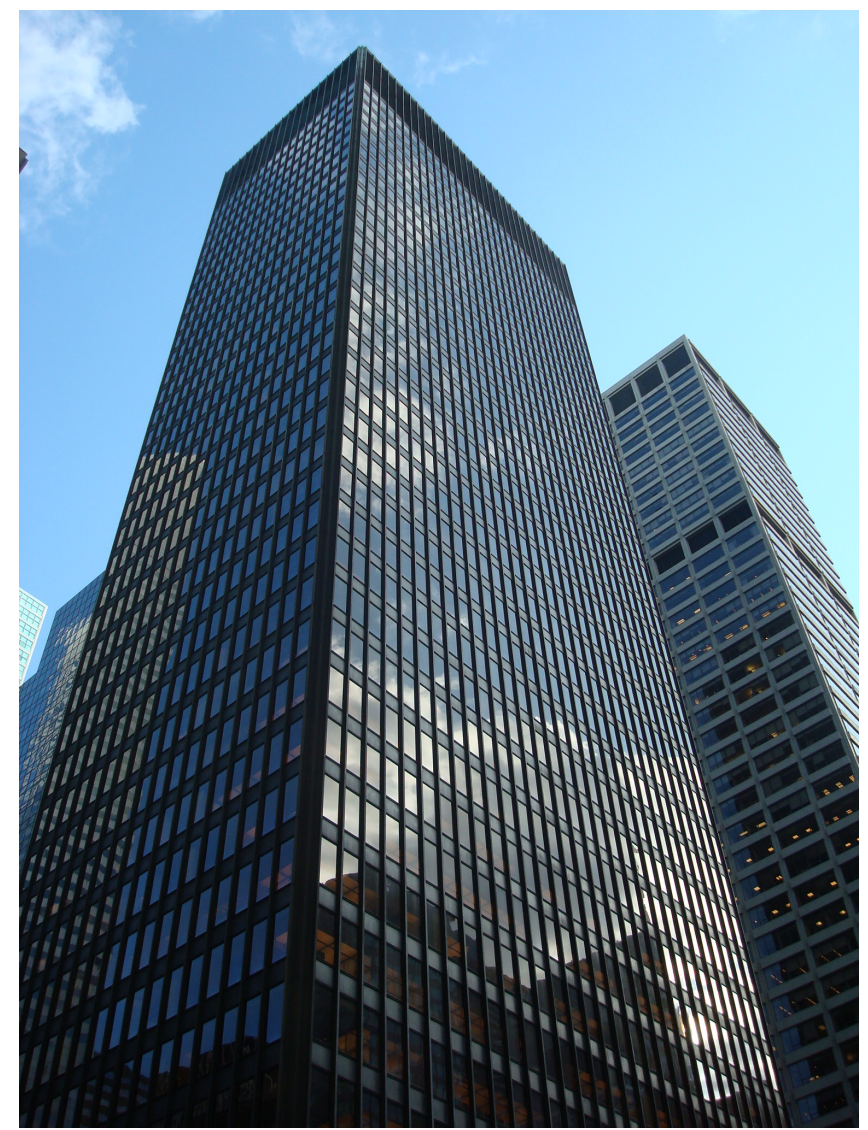

Figura 1. Mies van der Rohe. Edificio Seagram (Nueva York, 1958). Fuente: Julia Rey Pérez. 
Paralelamente a esta remodelación de los grandes edificios de oficinas, el salto del pequeño comercio al shopping center, que encuentra su origen en el periférico paisaje norteamericano, invadirá las ciudades de grandes contenedores -con una arquitectura anónima- que buscarán atraer clientes a partir de la transmisión de sus valores corporativos, cobrando especial importancia la dimensión como un mecanismo para abrumar tanto al ciudadano como a esos pequeños comercios con los que pretendían competir. Por una parte, en España, aparecen hitos urbanos como Mercadona, Decathlon, Ikea, Alcampo o Continente, que se asocian al comercio moderno -a pesar de que su arquitectura se limite a una simple caja de grandes dimensiones-, y se mezclan con otros en los que el diseño es encargado a arquitectos famosos. Un ejemplo de este último caso lo pone Virgilio Vercelloni, con el edificio construido por Frank Lloyd Wright para el gran negocio de regalos Morris Gift Shop en San Francisco, en 1948, y que hoy alberga la Xanadu Gallery. La excepcionalidad de este edificio desde el punto de vista de la comunicación reside en el diseño de su fachada, planteada como un muro de ladrillo compacto que se enfrenta y posiciona a una calle llena de gentío y movimiento. No hay ventanas, únicamente un arco clásico que se abre sugiriendo la entrada a un lugar excepcional. En este caso, la elegancia y discreción de la arquitectura de Wright iba de la mano del estatus de la empresa y del cliente al que iba dirigida (Vercelloni, 1993: 244).

Estas empresas buscaban la originalidad y destacar entre el resto de edificios circundantes, reclamando la atención del ciudadano a través del contenedor, como paso previo para que entrara en la construcción y conociese así su oferta. En este sentido, hay algunos ejemplos, en concreto de arquitectos posmodernos como Venturi, Graves o Stern, que ponen de manifiesto de manera clara esa intención de llamar la atención o de destacar en relación a los edificios cercanos. Un caso ilustrativo es el del Mitsubishi UFJ Financial Group japonés, que contrató al estudio Neil M. Denari Architects de Los Ángeles para que reinventara un nuevo espacio para la organización, partiendo de la idea de que cada edificio debía erigirse como un espacio de encuentro de la entidad con el cliente, por lo que la marca debía estar presente en todo momento. La primera de estas sedes fue erigida en el distrito de Shibuya, en Tokio (2004), y posteriormente el estudio se encargó de diseñar las de Nagoya y Kobe (2006) y las de Umeda y Ginza (2007), diferentes proyectos que cuentan con un diseño propio pero siempre "bajo un estilo y concepto en común que hace de la marca un sello impactante y reconocible dentro del denso entorno urbano en el que se encuentra" (Bahamón y Cañizares, 2008: 126) ${ }^{1}$.

A la tendencia de las grandes empresas de utilizar la arquitectura como medio de difusión de su identidad, tanto en lo que se refiere al diseño exterior como al interior, ya sea dirigida al cliente 0 al trabajador, se sumarán también otras entidades como emisores, desde instituciones culturales y deportivas hasta las propias ciudades, que ven la necesidad de crear una imagen de marca única, sólida y diferenciable como medio de reclamo de turistas e

\footnotetext{
${ }^{1}$ Para más información sobre estas construcciones y otros proyectos del estudio arquitectónico de Neil M. Denari, véase su sitio web (http://www.nmda-inc.com/filter/commercial/MTFG-Shibuya-2004). Consultado el 12 de septiembre de 2013.
} 
inversores o, simplemente, para hacerla más confortable a sus habitantes -actuales y potenciales-. Ejemplos como el edificio de la Administración Pública de Michael Graves en Portland (1982) o la Piazza d'Italia de Charles Moore en New Orleans (1978), ilustran las diversas estrategias que se pueden dar entre arquitecto y empresa a la hora de transmitir diversos valores. La proliferación de rascacielos vinculadas con la banca, de obras arquitectónicas que albergan museos (en los que no se sabe que es lo que acude a ver la población si el contenedor o el contenido), de grandes estadios deportivos, de ciudades de la cultura o de grandes obras de infraestructuras, es un negocio imparable entre empresa y arquitecto.

\section{El arquitecto como marca versus la marca del promotor}

A pesar de su potencial comunicativo, tradicionalmente ha sido la semiótica la que más se ha preocupado por el estudio de la arquitectura como comunicación simbólica y no tanto la comunicación en un sentido explícito (Mathews, 2010:7). En este sentido, las entidades públicas y privadas son cada vez más conscientes de la necesidad de incluir esta variable como parte del plan estratégico de comunicación de la organización. De esta forma, la funcionalidad que proporciona una nueva infraestructura debe ponerse en consonancia con la transmisión de los valores de esta. En otras palabras, de poco sirve un nuevo edificio o complejo si su diseño, tanto exterior como interior, no transmite la identidad corporativa de la organización. En esta línea, es necesario prestar atención a la interpretación que los receptores (Ilámese ciudadanos, turistas, etc.) hacen de la construcción, intentando dilucidar si ésta coincide con el significado que pretendía el arquitecto o el que encargó la obra, al tiempo que las marcas deben ser conscientes de que todos aquellos elementos que las rodean no serán decodificados - presumiblemente- de la misma forma en el presente que en el futuro. $Y$ al igual que cambian los anuncios o evolucionan las mascotas publicitarias, también sus edificios deben remodelarse y adaptarse a los nuevos contextos. "El gran problema de la arquitectura a la hora de contribuir a la creación de la imagen de empresa es su temporalidad, su carácter de obra concluyente, definitiva y duradera", un obstáculo que podría salvarse, en parte, con factores como la iluminación o la decoración que complementan la construcción (Rodríguez Centeno y Rodríguez Centeno, 1997: 46).

Pero no solo las construcciones en sí se utilizan como canales de difusión de los valores identitarios, sino que además, su inauguración/remodelación se emplea como excusa para ganar cobertura mediática y notoriedad. Persiguiendo este último objetivo, las organizaciones buscan rodearse de renombrados arquitectos, cuya fama repercuta favorablemente en su marca, una estrategia parecida a la que se implementa en publicidad cuando se contrata un personaje famoso para que difunda $y$, en definitiva, venda las bondades del producto o servicio. Por lo tanto, al igual que no todos los famosos tienen la misma eficacia a la hora de ser usados como reclamo por las empresas, no todos los arquitectos servirán igualmente a los objetivos de todas las organizaciones. Al fin y al cabo, cuando una entidad utiliza un canal externo de difusión de sus valores, debe tener en cuenta 
que lo que está haciendo es asociar su nombre al de dicho canal. En este sentido, cuando una empresa, pública o privada, contrata a un personaje público, llámese Rafa Nadal, Beyoncé o Frank Owen Gehry, directa o indirectamente está asociando su propia marca a la de dicho personaje.

En este punto surge una importante cuestión: ¿es más importante el arquitecto o la obra arquitectónica? La respuesta lógica sería ninguno de los dos aisladamente sino la suma de ambos, y, desde el punto de vista de la estrategia de comunicación de una organización, pública o privada, no debería haber otra posible. La construcción final, ya sirva como establecimiento de venta, sede de oficinas o fábrica, será susceptible de convertirse en símbolo y bandera de la empresa, pero, a su vez, esta notoriedad podrá verse aumentada en función de quién haya sido el arquitecto del edificio. Y lo mismo ocurriría en el caso de las ciudades, cuyo turismo puede verse incrementado en función de los monumentos que en ella se puedan visitar y disfrutar. El arquitecto, pues, funcionaría más como una herramienta de comunicación que como emisor del mensaje, rol que debería ser exclusivo de la entidad (empresa privada, ciudad, etc.). Sin embargo, aquí se plantea un importante problema y es que el arquitecto también posee su propia marca, fraguada a lo largo de los años y de las construcciones realizadas, y querrá conservarla intacta, independientemente del trabajo para el que le contraten. Por tanto, se da aquí un conflicto de intereses entre arquitecto contratado y organización contratante. El primero diseñará un edificio en función de los valores de la segunda, siempre y cuando no entre en conflicto con sus propios valores y características que posee como creador. La entidad, por su parte, deseará beneficiarse de la reputación del arquitecto, siempre y cuando se mantenga intacta su identidad corporativa, a no ser que su objetivo sea, precisamente, la renovación de la misma, en cuyo caso tampoco sería conveniente que esta coincidiera con la del arquitecto.

Una empresa privada, una institución pública o una ciudad podrán (y deberán) ser reconocidas a partir del simple visionado de sus edificios más emblemáticos los cuales podrán, a su vez, asociarse con un arquitecto o arquitecta determinados. El problema aparece cuando, en primera instancia, la construcción es fácilmente atribuible al diseñador, pero no es posible asociarla a una organización o población concretas, perdiendo así su verdadera utilidad en cuanto a transmisión de valores se refiere. Al respecto cabe preguntarse ¿quién se pone a disposición de quién? Con toda probabilidad, si el encargo se hiciera a arquitectos que no fuesen de renombre internacional, es la empresa la que marca las directrices, pero no se debe olvidar que la arquitectura de marca hoy en día es utilizada por la mayoría de las administraciones como un reclamo turístico. Cada vez más ciudades cuentan con algún hito que protagoniza su paisaje urbano, un museo mediático o una ciudad de la cultura.

Piénsese en marcas como Hermés, Prada o Chanel, todas ellas relacionadas con el universo de la moda y el diseño y que, por tanto, buscarán transmitir la exclusividad que caracteriza a sus valores corporativos. En palabras de Jiménez Marín y Caro González, sus "edificios se están repartiendo, en los últimos años, por la geografía mundial escogiendo en cada caso el 
lugar idóneo, más emblemático y visible con el fin de conseguir una reacción estética que implique una percepción mayor de su nombre de marca $y$, por tanto, un aumento de las ventas" (2006: 241). Se piensa así en nuevos espacios arquitectónicos donde mezclar el consumo, el placer, la comunicación y la cultura; en definitiva, ofrecer al consumidor una experiencia única, que pueda derivar en la adquisición de la oferta de la entidad, pero que a priori va mucho más allá de una simple transacción económica. En esta línea, hasta la fecha se pueden destacar cuatro premios Pritzker que se han unido a importantes marcas de moda: Rem Koolhas, Herzog \& De Meuron, Renzo Piano y Zaha Hadid.

El primero, junto con sus socios de OMA (Office for Metropolitan Architecture), aparte de construir el Prada Transformer en Seúl -un pabellón temporal que fue desmontado el 30 de septiembre de 2012-, reconvirtieron en 2001 el edificio Guggenheim del Soho en el New York's Prada Epicenter, situado en el número 575 de Broadway Avenue (Figura 2). Por su parte, el tándem suizo Herzog \& De Meuron son los creadores del Prada Aoyama Epicenter (2003), ubicado en una de las zonas de Tokio donde la moda y el diseño cobran una especial importancia. Los rombos de vidrio que configuran la fachada permiten que la perspectiva del visitante esté en continuo cambio, tanto desde dentro como fuera del recinto ${ }^{2}$. Los productos cambian para el transeúnte que pasea por la calle, pero también lo hace la ciudad para el consumidor que se haya dentro del local. De esta forma, edificio, marca y entorno mantienen una relación sinérgica para ofrecer al posible visitante una experiencia de consumo diferente, a la par que se convierte en un reclamo para turistas.

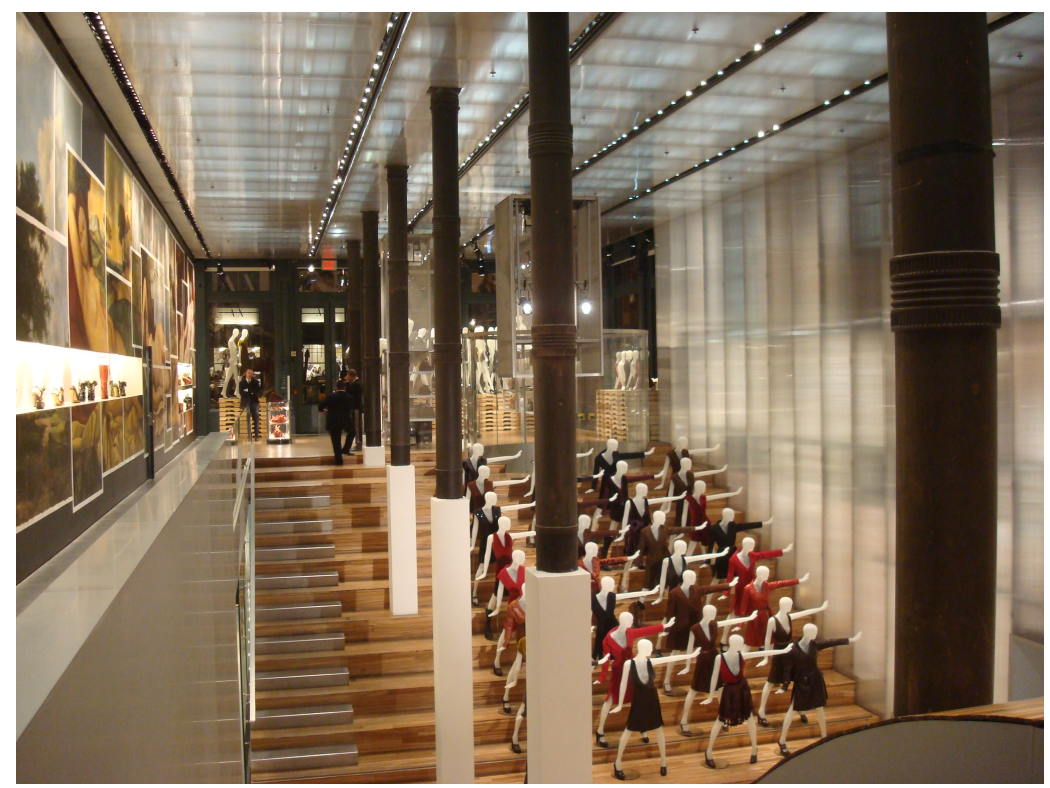

Figura 2. Rem Koolhas. New York's Prada Epicenter (Nueva York, 2001). Fuente: Julia Rey Pérez.

\footnotetext{
2 Se puede obtener más información sobre dicho edificio en el sitio web de los arquitectos (http://www.herzogdemeuron.com/index/projects/complete-works/176-200/178-prada-aoyama.html). Consultado el 25 de junio de 2013.
} 
También en Tokio se encuentran las obras que los japoneses Kasuyo Sejima y Ryue Nishizawa y Toyo Ito idearon para Dior y Tod's, respectivamente, o la Maison Hermès, que la firma francesa encargó al italiano Renzo Piano. Por su parte, otra entidad francesa, Chanel, contrató a la arquitecta iraquí Zaha Hadid para que diseñara un edificio nómada -el Chanel Mobile Art-, que debía recorrer entre 2008 y 2010 las ciudades de Hong Kong, Tokio, Nueva York, Londres, Moscú y París. Una gira que, no obstante, fue interrumpida como consecuencia de la crisis financiera.

En definitiva, arquitectura y moda han sellado un pacto que cada día ofrece más ejemplos de cómo la primera puede convertirse en un magnífico escaparate de los valores corporativos de las diferentes marcas. Como señala Eva Dallo, "la arquitectura comercial permite que muchos disfruten de una arquitectura que, en su versión residencial, se reserva a unos pocos", a la par que ofrece "la oportunidad de encarnar conceptos abstractos como los valores de la marca, evocando sensaciones concretas a través del diseño, como hacen la publicidad y el marketing" (2005: 6).

\section{Arquitectura, ciudad y comunicación}

También las ciudades, como si fuesen productos de consumo o marcas, están configurando su propia identidad con el objetivo de ser más competitivas (Muñiz Martínez, 2007: 171), una identidad que pasa por la re-construcción del paisaje urbano con el fin de otorgarle un valor diferencial, algo fundamental a partir del siglo XIX, "cuando la ciudad se proclama por vez primera como objeto de consumo, espacio para el espectáculo y el entretenimiento" (Moya, 2011: 228). Este nuevo modelo de ciudad necesita de nuevos hitos urbanos que la vinculen directamente con el progreso y la tecnología, lo que ha conducido a construir compulsivamente determinadas construcciones muy distantes de la historia, de la cultura y del urbanismo de la propia ciudad. En este sentido, cabe señalar que, en su momento, la arquitectura moderna se consideró como un obstáculo para la comunicación de los valores políticos del poder y una manera de acabar con la diversidad cultural en el paisaje de la ciudad (Frampton, 1998), aún dominado por las cúpulas de las grandes iglesias barrocas y renacentistas construidas en la época de esplendor, configuradas como símbolos del poder religioso. Espacialmente, estas construcciones eran de mayores dimensiones y de mayor altura para dominar el paisaje urbano y comunicar ese mensaje simbólico (Venturi, 1978: 35). Así, tomando como referencia, por ejemplo, las representaciones pictóricas del paisaje urbano de Sevilla (o alguna ciudad europea análoga), se puede identificar un precario caserío de edificaciones de entre una y dos plantas, en medio del cual se eleva imponente la conocida como "montaña hueca" de la catedral hispalense. La presencia y la fuerza de estas obras arquitectónicas eran una traducción del poder eclesiástico con el que los ciudadanos debían convivir.

Al respecto, cada época decidía cuál era la arquitectura más apropiada para comunicar los valores representativos de su momento histórico. Los edificios religiosos dejan paso a las 
grandes empresas protagonistas de las urbes contemporáneas, si bien con una clara diferencia: mientras que las grandes catedrales e iglesias que se erigieron en las ciudades europeas estaban pensadas para la vida en comunidad, los grandes hitos urbanos modernos se configuran, en su mayoría, como espacios de grandes dimensiones que albergan a multitud de ciudadanos anónimos sin conexión alguna entre ellos (Venturi, 1978: 76).

Sin embargo, el problema fundamental de esta arquitectura de marca es que adquiere mayor protagonismo que la ciudad en la que se inserta, perdiendo en este sentido toda su función. Al observar un puente del arquitecto Santiago Calatrava, inmediatamente se reconoce su autoría, pero no es tan sencillo identificar su ubicación, de modo que si no se recurre a otros elementos característicos de la ciudad, el receptor no podrá estar seguro si se encuentra observando una imagen de Valencia, Mérida, Murcia, Orleans, Bilbao, Sevilla, Ondárroa, Dublín, Buenos Aires, Haarlemmermeer, Reggio Emilia, Venecia, Jerusalén o Atenas. Y algo parecido sucede con las torres, estaciones, auditorios... del arquitecto, haciendo patente que la marca Calatrava y los valores identitarios que la acompañan están por encima del valor de la propia institución que lo contrata.

Arquitectos como el brasileño Oscar Niemeyer, el estadounidense Frank Owen Ghery, el alemán Peter Eisseman, la iraquí Zaha Hadid o el holandés Rem Koolhaas, tienen obras en diferentes ciudades del mundo. Se trata de grandes encargos realizados por Administraciones que desean transmitir ( $y$ ser recordadas por) su gran capacidad de gestión o por empresas privadas que manifiestan la dimensión de sus negocios, como es el caso de la Torre Cajasol, encargada por La Caixa al arquitecto argentino César Pelli, o la Torre Agbar, realizada por el arquitecto francés Jean Nouvel y que se ha erigido como símbolo iconográfico de la ciudad de Barcelona por encima incluso de la Sagrada Familia o Montjuic (Gaona Pisonero, 2007: 182).

Uno de los problemas que puede tener la arquitectura para comunicar es la temporalidad. En su momento es concebida como una obra de arte y su efecto comunicador responde en mayor medida al efecto estético, tanto por las cuestiones formales como por las morfológicas, unas cualidades que podrían ser aprovechadas por el empresario (Caro González, 1996: 81). Pero el arte pasa de moda, lo que obliga a hacer una profunda reflexión y análisis de qué imagen desea transmitir la empresa, tanto en el medio como en el largo plazo (1996: 85). En ese caso, la fundación Guggenheim se puede poner como ejemplo de empresa que elige los edificios y arquitectos más significativos de cada época como comunicadores de su arquitectura.

A pesar de que el museo Solomon R. Guggenheim de New York fue el primero de los museos creados por la fundación homónima en 1937, no salta a la fama a nivel internacional hasta que se traslada al edificio diseñado por el arquitecto Frank Lloyd Wright en 1959 (Figura 3). Se trata de un museo moderno que alberga una colección de arte moderno y, en el momento de elegir al arquitecto para el museo, la baronesa Hilla von Rebay eligió al arquitecto más famoso del momento. Lo mismo ocurrió 34 años después cuando se eligió a Frank Ghery en 
1993 para la construcción del museo Guggenheim en Bilbao y en 2006 para la creación de otro museo en Abu Dhabi por el mismo arquitecto. Estos ejemplos ponen de manifiesto cómo las empresas, en este caso culturales, eligen a los arquitectos o su arquitectura para transmitir su poder y los valores que abanderan y definir de este modo su presencia en el ámbito internacional. De hecho, y como mantiene Susana López Pérez, la visibilidad de la ciudad de Bilbao, buscada a través del Guggenheim, convierte al museo no solo en "una construcción arquitectónica de renombre" sino en "una estrategia [...] para otorgar a Bilbao esa pretendida visibilidad internacional" (2007: 206).

Aunque es difícil adaptar los nuevos edificios al entorno para preservar la identidad de la ciudad o intentar modificarla sin que esta desemboque en una ruptura demasiado brusca de la imagen percibida por ciudadanos y turistas, resulta más sencillo construir (o reconstruir) una ciudad de la nada. En este sentido, la nueva marca-ciudad adquirirá una identidad más sólida y los valores transmitidos estarán mejor definidos, a la par que las corporaciones privadas tendrán un mayor peso frente a la riqueza cultural de la región, haciendo del consumo el principal atributo a explotar. Un ejemplo de esta remodelación puede observarse en el emirato árabe de Dubái y, de forma más evidente, en Las Vegas (Figura 4). Creada, diseñada y planificada como una empresa, esta ciudad del estado de Nevada se ha configurado como paradigma de este nuevo fenómeno urbano donde la unión entre arquitectura y empresa es perfecta, y donde los valores y métodos comerciales se erigen como los protagonistas de la conformación del lugar (Venturi, 1978).

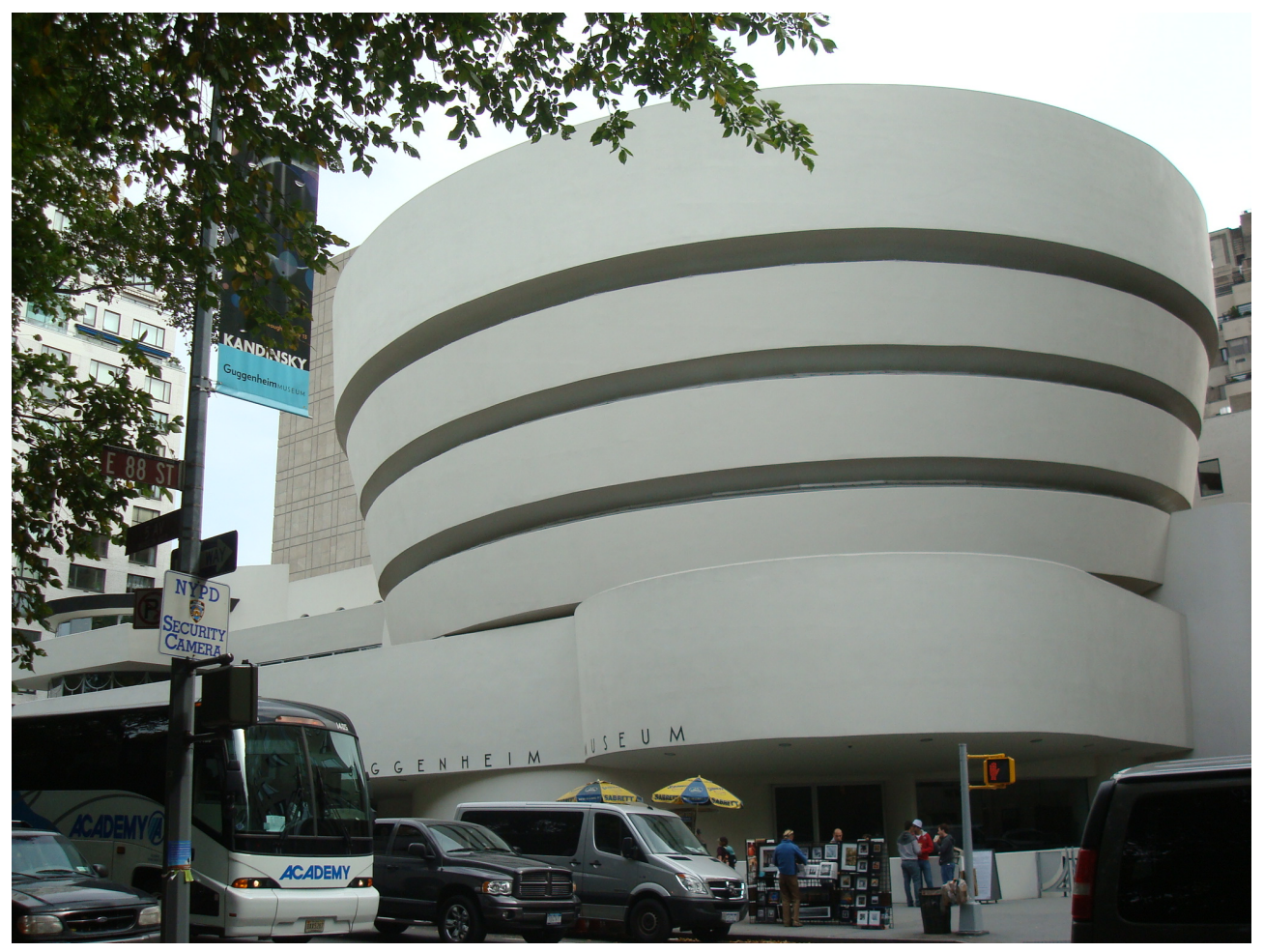

Figura 3. Frank Lloyd Wright. Museo Solomon R. Guggenheim (Nueva York, 1959). Fuente: Julia Rey Pérez. 


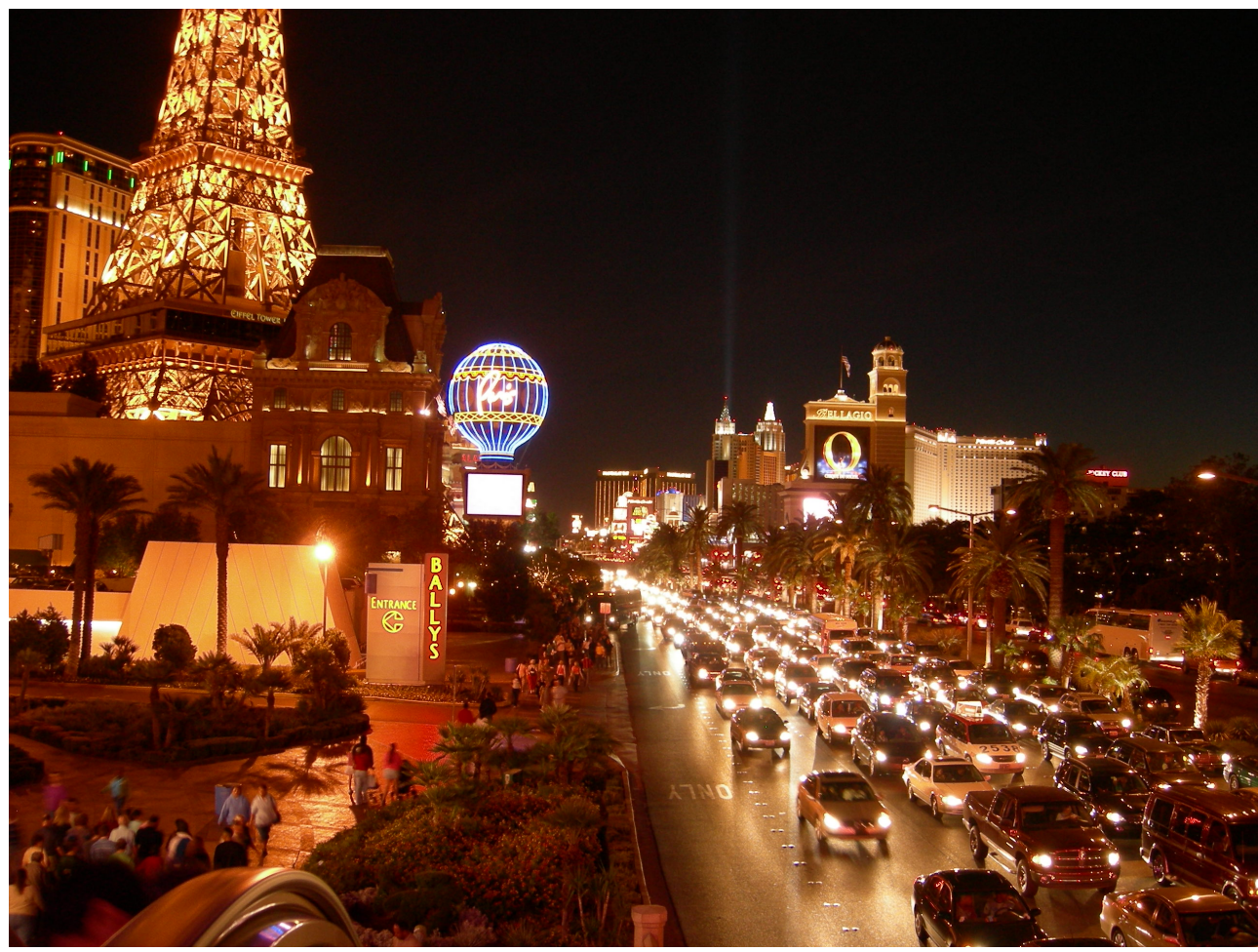

Figura 4. Las Vegas (Nevada, 2005). Fuente: Plácido González Martínez.

La vía comercial como origen del asentamiento urbano era una cuestión ya conocida en Europa, debido a que numerosas agrupaciones edificatorias han nacido a lo largo de las vías de acceso a las ciudades, muchas de ellas rutas comerciales por las que se transportaban diversas mercancías. Sin embargo, en el caso de Las Vegas desde el principio se plantea la "vía comercial" (strip), protagonizada por una arquitectura cuyo mensaje está abanderado por los valores del consumo. Baste como ejemplo el consejo que se dio a las estaciones de servicio para que imitasen la arquitectura de los casinos en aras de la unidad visual (1978: 13). Sin embargo, a pesar de este protagonismo del consumo, también puede verse la ciudad como "una gran locomotora cultural" (1978: 12) que "reafirma el papel del simbolismo en la arquitectura" (1978: 19). Las Vegas se erige así como un completo y paradigmático ejemplo de comunicación arquitectónica, que pasa de la comunicación del espacio a la arquitectura de la comunicación, de modo que "la comunicación domina al espacio en cuanto elemento de la arquitectura y del paisaje" (1978: 29). La arquitectura de Las Vegas ha construido un nuevo paisaje de grandes dimensiones y altas velocidades; diferentes carteles conectan con los elementos dispersos en su skyline, a distintas distancias y percibidos a rápida velocidad. En definitiva, la composición arquitectónica del strip transmite un mensaje comercial protagonizado por la máxima del "todo es posible", donde el sueño del éxito estadounidense se radicaliza, y los elementos se disponen el escenario para el desarrollo del consumo más exacerbado. 


\section{A modo de conclusión}

Más allá de su estudio desde una perspectiva estrictamente semiótica, las construcciones arquitectónicas se configuran como una importante variable en la comunicación de la identidad corporativa, tanto de una empresa privada como de una organización social o política o de una ciudad. Desde sus inicios, la arquitectura se pone al servicio del poder (político, económico, religioso), que recurre a ella con el objetivo de afianzar su posición y recordar a los ciudadanos qué posición corresponde a cada uno. Un fenómeno que, no obstante, encuentra su traslación en la época contemporánea, donde las ciudades están en constante transformación como consecuencia de la construcción, reconstrucción o remodelación de diferentes edificios corporativos que pretenden destacar en el paisaje urbano, llamando así la atención de ciudadanos, consumidores y turistas. ¿Acaso son tan diferentes las monumentales construcciones de Prada de las imponentes catedrales góticas?

Es cierto que, con el paso del tiempo, los promotores de estas obras arquitectónicas han sufrido una evolución. Cabe afirmar, pues, que de un promotor -que podría denominarsecompacto en el sentido de que está constituido por los poderes políticos y religiosos, mutua y fuertemente vinculados, y que son los únicos que dominan en el pasado, se ha pasado a un promotor -que podría denominarse- difuso en el sentido de que no está constituido por uno o dos poderes, sino por varios, y que son los que, en diferentes grados, dominan el panorama actual: el poder económico, el empresarial y el de la moda, a los que hay que sumar los poderes de antaño, el político y el religioso. De esta forma, del protagonismo absoluto del poder político y religioso, impulsores de los grandes palacios y fortalezas, iglesias y catedrales, ha cedido el paso a un nuevo panorama en el que son las grandes corporaciones las que ocupan el primer puesto en cuanto a promotores de este tipo de construcciones, como ilustran los casos de las grandes corporaciones bancarias, empresariales o las firmas de moda. De esta forma, los dos poderes anteriores quedarían relegados a un segundo plano, perdiendo influencia con respecto a etapas anteriores, lo cual no debe confundirse con que hayan dejado de promover determinados complejos arquitectónicos que contribuyan a consolidar su poder en la sociedad. Sirvan como ejemplos las obras del Metropol Parasol de Sevilla del arquitecto alemán Jürgen Mayter, la Filarmónica del Elba en Hamburgo de Herzog \& De Meuron o la Ciudad de la Cultura de Galicia que Peter Elsenman ideó para la ciudad de Santiago de Compostela, todas ellas suscitadas por determinados equipos de gobierno de las respectivas ciudades. $O$, ya en el plano religioso, construcciones como la catedral de Nuestra Señora de Los Ángeles (Los Ángeles, California), obra del arquitecto español Rafael Moneo entre 1998 y 2002, la catedral Metropolitana Nossa Senhora Aparecida de Brasilia, construida por Oscar Niemeyer en 1970 (Figura 5), o la catedral Metropolitana de San Sebastián en Río de Janeiro, obra del arquitecto Edgar de Oliveira finalizada en 1976, que si bien de una manera menos agresiva, sin duda transmiten el poder de la Iglesia. No obstante, cabe concluir diciendo que, al margen de la promoción que en este sentido hagan los promotores tradicionales, son los promotores modernos (las corporaciones) los que dominan el panorama actual. 


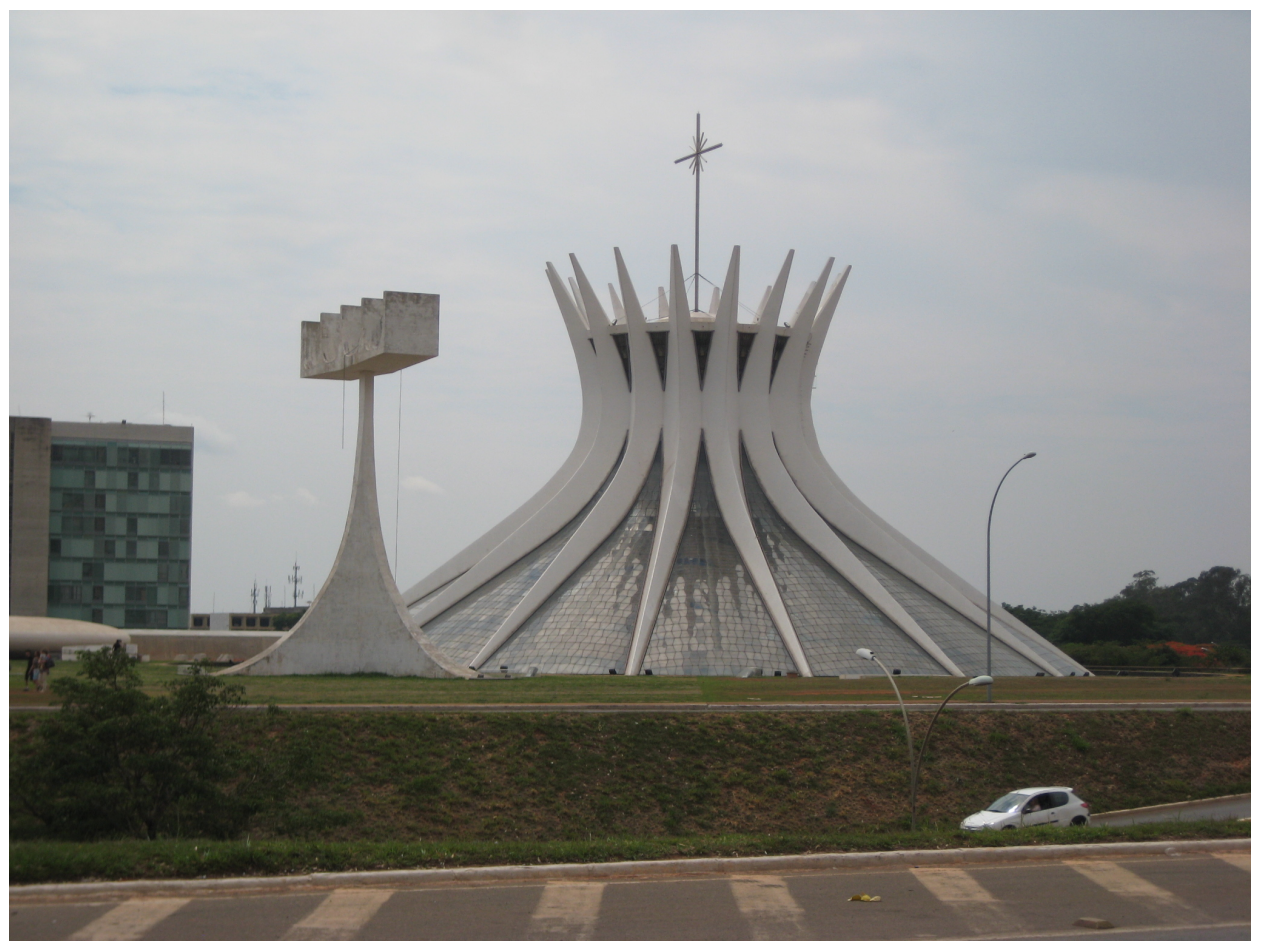

Figura 5. Oscar Niemeyer. Catedral Metropolitana Nossa Senhora Aparecida (Brasilia, 1970). Fuente: Julia Rey Pérez.

En cualquier caso, independientemente de quién sea el promotor de la construcción, la conclusión que debe extraerse del presente artículo es la importancia que tienen las obras arquitectónicas como instrumento comunicativo, lo que insta a las diferentes entidades y organizaciones a planificar y diseñar las construcciones de sus edificios como si de cualquier otra campaña de comunicación se tratara. Como ya se ha indicado, una de las limitaciones que pueden encontrar estas edificaciones en tanto que recursos comunicativos es su perpetuidad espacio-temporal, pero incluso esta puede verse subsanada con la modificación de ciertos elementos complementarios, como la decoración, que permitirá una mejor adecuación a la evolución de las marcas. En definitiva, la sede de una entidad bancaria, un partido político o una agencia de viajes debe entenderse, al mismo tiempo, como canal y mensaje que transmitirá los valores y la identidad de la organización, y al igual que una campaña publicitaria no puede quedar totalmente supeditada a los designios del equipo creativo, el edificio no puede estar condicionado a los intereses y gustos del arquitecto.

\section{REFERENCIAS BIBLIOGRÁFICAS}

BAHAmón, Alejandro y CAÑIZARES, Ana (2008): Banca. Arquitectura corporativa, Barcelona, Parramón

BenÉvolo, Leonardo (1984): Historia de la arquitectura del Renacimiento: la arquitectura clásica (del siglo XV al siglo XVIII), Barcelona, Gustavo Gilli. 
CARO GonzÁlez, Francisco José (1996): "La arquitectura de la empresa: un elemento al servicio de la comunicación comercial", en Questiones Publicitarias, vol. 1, no 5, pp.75-86.

Dallo, Eva (2005): Shop Design, Cologne, Daab.

FRAMPTON, Kenneth (1998): Historia crítica de la arquitectura moderna, Barcelona, Gustavo Gili.

Gaona Pisonero, Carmen (2007): "Nuevos símbolos urbanos desde la publicidad", en Antonio J. Baladrón Pazos, Esther Martínez Pastor y Marta Pacheco Rueda (dir.), Publicidad y ciudad. La comunicación publicitaria y lo urbano: perspectivas y aportaciones, Sevilla, Comunicación Social, pp. 172-188.

JimÉnEz MARÍn, Gloria y CARO GONZÁlez, Francisco Javier (2006): "La arquitectura comercial como soporte para la creación de identidad en el sector de la moda", en Josep Rom y Joan Sabaté (eds.), Revisemos las teorías de la creatividad. III Simposum de profesores universitarios de creatividad publicitaria, Barcelona, Trípodos EXTRA, pp. 235-244.

LóPEZ PÉREZ, Susana (2007): "Arte y cultura como valor añadido a la publicidad: Bilbao y el museo Guggenheim", en Antonio J. Baladrón Pazos, Esther Martínez Pastor y Marta Pacheco Rueda (dir.), Publicidad y ciudad. La comunicación publicitaria y lo urbano: perspectivas y aportaciones, Sevilla, Comunicación Social, pp. 189-207.

MATTHEWS, Geoff (2010): "Ingenious, eloquent and persuasive? Towards a critique of architecture as communication", en The Cultural Role of Architecture, 2425 June 2010, University of Lincoln. Disponible en: http://eprints.lincoln.ac.uk/7076/1/Matthews_-_Ingenious_Eloquent_and_ Persuasive.pdf (consultado: 26/06/2013).

Moya Pellitero, Ana María (2011): La percepción del paisaje urbano, Madrid, Biblioteca Nueva.

MuÑIZ MARTínEZ, Norberto (2007): "Marketing de ciudades: de la gestión estratégica y de infraestructuras a la creatividad y los valores", en Antonio J. Baladrón Pazos, Esther Martínez Pastor y Marta Pacheco Rueda (dir.), Publicidad y ciudad. La comunicación publicitaria y lo urbano: perspectivas y aportaciones, Sevilla, Comunicación Social, pp. 149-171.

Rodríguez Centeno, J. C. y Rodríguez Centeno, C. (1997): "La arquitectura como elemento de formación de la imagen corporativa", en Juan Rey (ed.), Algunas consideraciones sobre la comunicación empresarial e institucional, 41-48.

VENTURI, Robert; ScotT Denise; IzENOUR Steven (1978): Aprendiendo de Las Vegas. El simbolismo olvidado de la forma arquitectónica, Barcelona, Gustavo Gili. 
VERCELLONI, Virgilio (1993): Comunicare con L'Architettura, Milán, FrancoAngeli.

[Recibido: 11 de julio de 2013. Aceptado: 17 de septiembre de 2013]. 